\title{
HOSPITAL WASTE MANAGEMENT; TERTIARY CARE HOSPITALS
}

1. MBBS, PGD (Nutrition), MCPS, $\mathrm{MSc}$ (Community Health \& Nutrition), MPH

Associate Professor

Department of Community Health Sciences, Jinnah Medical \& Dental College, Karachi, Pakistan

2. MBBS, MPhil

Associate Professor

Department of Biochemistry

Bahria University Medical \& Dental College, Karachi, Pakistan

3. MBBS, MPhil

Associate Professor

Department of Pathology

Bahria University Medical \& Dental College, Karachi, Pakistan

Correspondence Address:

Dr. Murad Qadir

D 41 Block F North Nazimabad

Karachi 74700 Pakistan

muradqadir985@yahoo.com

Article received on:

06/02/2016

Accepted for publication:

$16 / 05 / 2016$

Received after proof reading: 04/07/2016

\section{INTRODUCTION}

The health care waste management is one of the major challenges in developing countries where hospital staff and surroundings are exposed to various risks due to inappropriate handling of the hospital waste. ${ }^{1}$ These wastes are potentially hazardous / infectious and their indiscriminate and unscientific management poses serious threats to human health. ${ }^{2}$ Mismanagement of the hospital waste results in environmental pollution and infections like typhoid, cholera, tuberculosis and many other diseases like Hepatitis, HIV and AIDS. ${ }^{3}$ It has been reported that the generation of hospital waste ranges from 0.5 to $2.0 \mathrm{~kg}$ per bed per day globally. ${ }^{4}$ Hospitals and other health care establishments in Pakistan produces a significant amount of waste, posing serious problems for its disposal. Previous studies conducted in Pakistan showed that approximately $2.0 \mathrm{~kg}$ of waste is produced /bed/day out of which 0.1 to $0.7 \mathrm{~kg}$ is labeled as hospital waste. ${ }^{5}$
It is important to note that not all hospital waste has the potential to transmit infection but due to the poor waste disposal practices by health care workers the infectious component gets mixed with non-infectious waste, so the entire bulk of hospital waste becomes infectious. ${ }^{6}$ Improper disposal practices of hospital waste affects the people who come in direct contact with it, like health workers, waste collectors and rag pickers. ${ }^{7}$

It is also seen thathospital stafflacks understanding and knowledge regarding waste management due to lack of awareness, inadequate training/ related courses. Also insufficient finance and human sources are the most common problems related to the health care waste. ${ }^{8}$

Knowledge and safe protocols employed by the hospital waste management staff is very important while managing hospital waste. Recycling of used syringes has emerged as a serious health issue specially doctors, other hospital staff and 
patients who becomes target of sharp injuries and infection. ${ }^{7,9}$ In Pakistan hospital waste is not only the source of diseases but also become the target of waste collectors who collect used syringes for recycling to be sold for financial purpose. ${ }^{10}$ Hospitals that lacks appropriate method for disposal of hospital waste such as incineration can result in open dumping of hospital waste in different areas of city. ${ }^{11}$

Hospital waste comprised of $15-20 \%$ of general waste but due to the improper collection and segregation there is mixing of the hospital waste with general waste and leads to serious threats to human health. ${ }^{12}$ In Pakistan there is no information regarding the management of the hospital waste among the health care workers who are responsible for the disposal of the hospital waste. ${ }^{13}$

Hence this study was conducted to assess the awareness regarding hospital/biomedical waste and the methods of effective waste disposal at tertiary care hospitals of Karachi.

\section{MATERIALS AND METHODS}

This cross sectional study was conducted over a period of six months from June 2014-Dec 2014. Study was conducted at 15 different tertiary care hospitals of Karachi which included government, charitable / trust and private sector hospitals. Hospitals were selected from the list of all tertiary care hospitals by quota sampling method.

A pre-designed questionnaire was filled by the supervisors / in charge of the hospital waste management staff and informal interviews were taken from the hospital waste management staff directly. The interviews were conducted at actual locations of the source of collection to the point of final disposal.

All the tertiary care hospitals included in the study had more than 100 bed capacity. Hospitals having less than 100 beds, maternity homes, clinics, dispensaries, basics health units, laboratories were not included in this study.
Data collected was analyzed on SPSS version 12

\section{RESULTS}

Among the fifteen hospitals selected in Karachi, five were in public sector, eight hospitals were in private sector where as two hospitals were charitable hospitals run by trusts. Out of these 15 hospitals selected in the study, $66.7 \%$ of hospital waste management staff was not having any knowledge regarding infectious and noninfectious waste disposal. Only $33.3 \%$ of the total staff had some knowledge about it.

\begin{tabular}{|c|c|c|}
\hline & Frequency & Percent \\
\hline Yes & 5 & 33.3 \\
\hline No & 10 & 66.7 \\
\hline Total & 15 & 100 \\
\hline Table-I. Knowledge of HCW team about infectious \\
\multicolumn{2}{|c|}{\begin{tabular}{l} 
and noninfectious waste \\
\hline
\end{tabular}} \\
\hline
\end{tabular}

\begin{tabular}{|c|c|c|}
\hline & Frequency & Percent \\
\hline Yes & 7 & 46.7 \\
\hline No & 8 & 53.3 \\
\hline Total & 15 & 100 \\
\hline Table-II. Status of the hospitals using their own \\
\end{tabular}

Figure-1 shows that only $27 \%$ of the under study hospitals (Four hospitals including one government and three private) were separating the infectious and noninfectious waste at the level of source while the remaining $73 \%$ of the total hospitals (eleven hospitals comprising of four government, five private and two trust hospitals) were not separating it at the level of source. Out of these eleven hospitals only two hospitals were separating the infectious and noninfectious waste at the level of collection point.

Only $20 \%$ of the total (three private hospitals) hospitals were practicing the separation of sharps by proper method of using colored containers while 27\% (Four hospitals including one government, two private and a charitable hospital) were using regular shopping bags. 53\% (eight hospitals that includes four government, three private and a charitable hospital) were not 
separating the sharps from other waste.

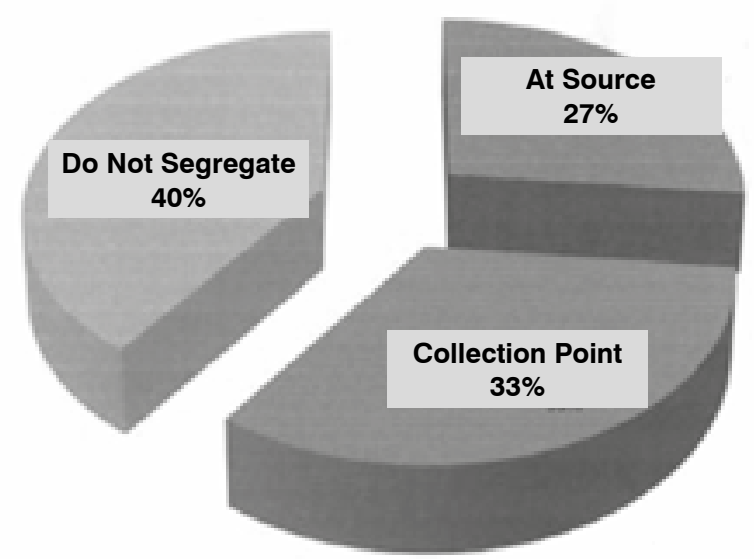

Figure-1. Showing the points of segregation of infectious and noninfectious waste
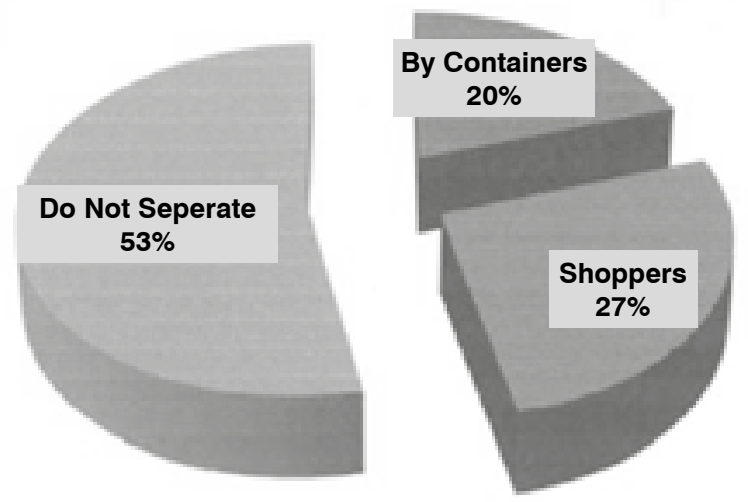

Figure-2. Showing the methods to separate sharps

Hospital waste management staff members of only one private sector hospital which is $6.7 \%$ of the total fifteen hospitals were vaccinated against hepatitis ' $\mathrm{B}$ ' and tetanus while staffs of remaining 93.3\% hospitals were not vaccinated against both diseases. Staff of ten hospitals (66.67\%) that include three public sector, six private sector and one trust hospital were vaccinated against hepatitis B only.

Eight hospitals (53.3\%) were not having their own incinerator facilities while only $46.7 \%$ (seven hospitals comprising of three government and four private sector) were using their own incinerator plants within the hospital premises.
This study gives an overall picture of poor management of hospital waste in most of the tertiary care hospitals of Karachi. The magnitude of hospital waste management is increasing day by day. This study revealed the facts by studying the knowledge gap of service providers and practices of the hospital waste management team. Also in Pakistan, hospitals whether in private or public sector are not following the guidelines of WHO regarding hospital waste management and also do not practice Pakistan bio-safety rules. ${ }^{12}$ Previous studies conducted in Pakistan and in neighboring countries have highlighted the lack of awareness among hospital waste management staff regarding disposal of waste. ${ }^{14,15,16}$

According to the results of this study only four hospitals were separating infectious and noninfectious waste at the level of source while two hospitals were separating it at the main collection point whereas nine hospitals were not segregating infectious and noninfectious waste material. A study conducted at a tertiary care hospital in Srinagar, Indian occupied Kashmir showed similar results where lack of segregation of hospital waste resulted in mixing of biomedical waste with general waste. ${ }^{17}$ Due to improper management of the biomedical waste the infectious waste gets mixed with solid waste and may get added to the ground water and spreads hazardous diseases. ${ }^{18} \mathrm{~A}$ study conducted in 150 health care institutions in Punjab, Pakistan also observed that the hospital waste was neither properly segregated nor transported or disposed in a scientific manner thereby posing immense risk to the patients, staff and even to public. ${ }^{19}$

It was also observed in our study that only three out of the total hospitals were separating sharps like syringes, surgical blades, sewing needles and other sharp objects by using colored containers while rest of the hospitals were not using any color coding system for the separation of sharps which is the main source of infections and communicable diseases specially hepatitis B, tetanus and HIV. These infections can be avoided if the syringes are disposed safely. ${ }^{8}$ Similar finding are given in previous studies regarding lack of knowledge 
and poor practices among lower staff about color coding system during waste management and use of personal protective equipments. ${ }^{20,21}$

Results of the study also revealed that staff members of only one hospital out of the total were vaccinated against hepatitis $B$ and tetanus which shows that very little fraction of hospital staff was vaccinated against these diseases. These results are similar to a study conducted in tertiary hospitals of Lahore where most of the staff like sweepers and others were not vaccinated against Hepatitis-B, Tetanus and other infectious diseases. ${ }^{22}$

Our study also revealed that only seven out of the fifteen hospitals have their own incinerator facilities for the disposal of infectious/hazardous waste and rest of the eight depend upon City District Government/Municipal committees and contractors. Most of the hospitals were having their incinerator plants within the premises of the hospital generating hazardous gases which is dangerous and threat to public health especially for those who are living and working around. This observation is similar to the observation made by Etusim (2013) who identified scarce incinerator facilities at selected hospitals in imo stateNigeria, whereas a study by Harhay (2009) have noted absence of incineration facilities in different hospitals of Kabul.

Thus this study reveals that there is a general lack of awareness regarding the hospital waste disposal among hospital waste management staff. There is also inadequacy seen in handling collection and storage of hospital waste.

\section{CONCLUSION}

According to the results of the study we came to the conclusion that there is an immediate need to enhance awareness as well as management of hospital waste disposal. There should be proper education and training of waste management staff. Recommended SOPs of Hospital Waste Management Program should be implemented at all levels.
Copyright@ 16 May, 2016.

\section{REFERENCES}

1. Hossain MS, Santhanam A, Nick Norulaini NA, Omar AK. Clinical solid waste management practices and its impact on human health and Environment: A review. Waste Manag 2011; 31:754-756.

2. Rao HP. Report: Hospital waste managementawareness and practices: a study of three states in India. Waste Manag Res 2008; 26:297-303.

3. Ullah JH, Ahmed R, Malik JI, Khan MA. Outcome of 7-S TQM technique for health care waste management. J Coll Physicians Surg Pak 2011; 21:731- 734.

4. Zhang HJ, Zhang YH, Wang Y, Yang YH, Zhang J, Wang $Y L$ et al. Investigation of medical waste management in Gansu Province, China. Waste Manag Res 2013; 31:655-699.

5. Hashmi SK, Shahab S. Hospital and Biomedical waste management. In: Iliyas M, Editor, Community medicine and public health. $4^{\text {th }}$ ed. Karachi: Time Publishers, 2003, pp. 426-437.

6. Sharma A, Sharma V, Sharma S, Singh P. Awareness of biomedical waste management among health care personnel in Jaipur, India. Oral Health and Dental Management 2013; 12(1):32-40.

7. Nema A, Pathak A, Bajaj P, Singh H, Kumar S. A case study: biomedical waste management practices at city hospital in Himachal Pradesh. Waste Manag Res 2011; 29:669-673.

8. Babanyara YY, Ibrahim DB, Garba T, Bogoro AG, Abubakar MY. Poor Medical Waste Management (MWM) Practices and its Risks to Human Health and the Environment: A Literature Review. International Journal of Environmental, Chemical, Ecological, Geological and Geophysical Engineering 2013; 7(11):766-773.

9. Ikram A, Hussain Shah SI, Naseem S, Absar SF, Ullah S, Ambreen $T$, et al. Status of hospital infection control measures at seven major tertiary care hospitals of northern Punjab. J Coll Physicians Surg Pak 2010; 20:266-70.

10. Khan MR, Fareedi F, Rashid B. Techno-economic disposal of hospital wastes in Pakistan. Pak $\mathrm{J}$ Med Res 2006; 45:41-45.

11. Gautam V, Thapar R, Sharma M. Biomedical waste management: incineration vs. environmental safety. Indian J Med Microbiol 2010; 28(3):191-200.

12. Kumar R, Khan EA, Ahmed J, Khan Z, Magan M, 
Nousheen et al. Health care waste management (HCWM) in Pakistan: current situation and training options. J Ayub Med Coll Abbottabad 2010; 22(4): 101105.

13. Qaiser S. Survey of sharp waste disposal system in clinics of New Karachi. J Pak Med Assoc 2012; 62(2): 163-4.

14. Yadavannavar M, Berad AS, Jagirdar P. Biomedical waste management: a study of knowledge, attitude, and practices in a tertiary health care institution in Bijapur. Indian J Community Med 2010; 35:170-1.

15. Soysal A, Simsek H, Soysal D, Alyu F. Management of health-care waste in Izmir, Turkey. Ann Ist Super Sanita 2010; 46:299-302.

16. Ruoyan G, Lingzhong X, Huijuan L, Chengchao Z, Jiangjiang $H$, Yoshihisa $S$, et al. Investigation of health care waste management in Binzhou District, China. Waste Manag 2010; 30:246-50.

17. S Khurshid, R Mathur, SR Shah, MA Bhat, R Ahmad. Study of Hospital waste management at Shri Maharaja Hari Singh Hospital in Srinagar. Int J Recent Scientific Res 2013; 4(9):1499-53.

18. AV Tiwari, PA Kadu. Biomedical waste management in India - A Review. Journal of Current Engineering and Technology 2013; 3(5):2030-33.

19. Ullah JH, Ahmed R, Malik Jl, Khan MA. Managing the health care solid waste in selected districts of Punjab. Pak J Med Sci 2010; 26(4):795-799.

20. Gyawali S, Rathore DS, Kc B, Shankar PR. Study of status of safe injection practice and knowledge regarding injection safety among primary health care workers in Baglungdistrict, western Nepal. BMC Int Health Hum Rights 2013; 13:3.

21. Chethana T, Thapsey H, Gautham MS, SreekantaiahP, Suryanarayana SP. Situation analysis and issues inmanagement of biomedical waste in select small health care facilities in a ward under Bruhat Bengaluru MahanagaraPalike, Bangalore. India. J Community Health 2013; 39(2):310-15.

22. Imdad S, Anwar S, Shoukat MS. Healthcare Waste: Evaluation of its Generation Rate and Management Practices in Tertiary Care Hospitals of Lahore. Annals 2013; 19(4):274-81.

23. Etusim, P. E., ljere, A.O., Melariri, P. E, Ogwo, P. A, Ikonne, A. Study on Solid Waste Generation and Characterization inSome Selected Hospitals in Okigwe, Imo State-Nigeria U. Journal of Educational and Social Research 2013; 3(4):337-43.

24. Harhay, M. O, Halpern D. S, Harhay J. S, Piero O. L. Health Care Waste Management: a neglected and growing public health problem worldwide. Journal Tropical Medicine and International Health 2009; 14:1-4.

\section{AUTHORSHIP AND CONTRIBUTION DECLARATION}

\begin{tabular}{|c|c|c|c|}
\hline Sr. \# & Author-s Full Name & Contribution to the paper & Author $=\mathbf{s}$ Signature \\
\hline $\begin{array}{l}2 \\
3\end{array}$ & $\begin{array}{l}\text { Dr. Murad Qadir } \\
\text { Dr. Rafat Murad } \\
\text { Dr. Naveed Faraz }\end{array}$ & $\begin{array}{l}\text { Concept, Data collection, } \\
\text { Data analysis } \\
\text { Manuscript writing, Data } \\
\text { collection } \\
\text { Data analysis, Discussion }\end{array}$ & Qfe \\
\hline
\end{tabular}

